\title{
A cost-based pricing analysis
}

\author{
Michail Katsigiannis \\ Department of Communications and Networking \\ Aalto University, School of Electrical Engineering \\ Helsinki, Finland \\ michail.katsigiannis@aalto.fi
}

\begin{abstract}
The high anticipated mobile data growth pushes mobile operators to rethink about the way they charge for mobile broadband. The purpose of this study is to analyze the cost-based pricing which provides fundamental information to mobile operators to form a pricing strategy. Assuming that the total network cost has to be recovered at a specific traffic level (pricedeterminant traffic level), the analysis shows that for real traffic level which is more than this price-determinant traffic level, the usage-based pricing is always preferable than the flat rate pricing. Whereas for real traffic level which is less than this price-determinant traffic level, the flat rate pricing is always preferable than the usage-based pricing. Also, the flat rate pricing level has to increase while the traffic level increases, unless more users join the network to share the cost or the total cost declines. On the contrary, adopting the usage-based pricing, the operator is able to decrease the unit price level while the traffic level increases.
\end{abstract}

Keywords - cost-based pricing; flat rate pricing; usage-based pricing; mobile broadband.

\section{INTRODUCTION}

One of the main managerial decision problems is pricing. In oligopolies such as mobile data communications market, the price is set mainly by the firms rather than the market forces. The estimation of the cost-based pricing determines the minimum price level and provides fundamental information for setting a pricing strategy. Often, the cost is more controllable than the revenues and therefore, a precise evaluation of the cost can assist in defining the minimum required revenues to avoid losses. Due to the rapid growth in mobile data traffic, the mobile operators rethink the way they charge for mobile broadband service. Currently in mobile broadband markets, most of mobile operators follow the successful pricing structure of fixed broadband service i.e., a monthly fixed rate per subscription. Thus, the flat rate dominates also in mobile broadband. However, there is a debate in industry and academia about the prevailing pricing mechanism in future mobile broadband market.

Molleryd et al. [1] show that the flat-rate tariff charged for mobile broadband service causes revenues to be decoupled from traffic and implicitly also from operating and investment costs (costs are dependent on traffic per user, but not revenues). Kesidis et al., [2] propose that this decoupling problem ("revenue gap") can be fixed with usage-based pricing which is advantageous both from the system perspective (reduces degree of overload) and individual users' perspective (increases their perceived utilization). Ljungberg and Boll [3] suggest among others that operators have to introduce new pricing models to drive revenue growth. Finally, Katsigiannis and Valagiannopoulos [4] show that the flat-rate tariff structure can be applied as long as marginal cost reductions are achieved. But, obviously, this marginal cost adjustment strategy cannot be followed forever. Then, a usage-based pricing structure should be adopted in order for revenues to follow the rapidly increasing traffic. On the other hand, some studies support the flat-rate tariff for mobile broadband services. For example, Mitomo et al. [5] demonstrates the existence of flat-rate preference in mobile services. Also, Blennerud [6], [7] conducts cost-benefit analyses based on real and forecasted costs and revenues and concludes that unlimited flat-rate with a fair-use clause is potentially more profitable for the operator than data usage plans. A marginal cost of 0.1 to 0.2 EURO per gigabyte and the ability to handle heavy users can give to operators the possibility of keeping the flat-rate tariff.

Motivated by the uncertainty of the future prevailing pricing mechanism, the paper compares the flat rate and the usage-based pricing. The purpose of this study is to use basic economic theory to conduct cost-based pricing analysis. The contribution of the study is the better understanding of flat rate and usage-based pricing, highlighting also the conflicting behaviors of the users and the operators. Finally, the paper provides fundamental information to mobile operators to form a pricing strategy. Even though the study focuses on mobile communications market, the analysis is applicable for other markets and operators such as internet service providers.

\section{COST-BASED PRICINGS}

The total cost curve and in particular its marginal and average cost analysis provides the information for the minimum pricing level i.e., the cost-based pricing. The mobile operator has to charge at least at the price level so as the total revenue (TR) to be equal to total cost (TC). This is the breakeven price which is the price for which the unit must be sold to cover the cost of its production or alternatively the price the user must pay to cover the cost of the total network. The first is referred to break-even usage-based pricing and the second to break-even flat rate pricing. In this study, a mobile operator is considered as a firm which produces mobile data traffic, calculated e.g., in terabytes per month (i.e., the unit is TB/month). Fig. 1 depicts the total cost curve and the total 
revenues curves for flat rate and usage-based pricing both in short- and long-run. In short-run (left figure), the total cost is the operating cost of the current network, whereas in long-run (right figure), the long-run total cost includes also the capital cost of future network investments.

The flat rate is the sharing of the total network cost to the users. Assuming that the mobile operator wishes to recover the costs at the traffic level $x_{p}$ in short-run, the break-even flat rate is $\mathrm{P}_{\text {flat }}=\mathrm{TC}\left(\mathrm{x}_{\mathrm{p}}\right) /$ users, so as $\mathrm{TC}\left(\mathrm{x}_{\mathrm{p}}\right)=\mathrm{TR}_{\text {flat }}\left(\mathrm{x}_{\mathrm{p}}\right)$. For unchangeable number of data users, the revenue curve $T_{\text {flat }}$ is constant over traffic level, since it does not depend on the traffic. At this price level $\mathrm{P}_{\text {flat }}$ and for a real traffic level $\mathrm{x}_{\alpha}$ (where $x_{\alpha}<x_{p}$ ), the mobile operator gains profits which are equal to the difference of the variable costs at the pricedeterminant traffic level and the real traffic level i.e., $\operatorname{VC}\left(\mathrm{x}_{\mathrm{p}}\right)$ $\operatorname{VC}\left(\mathrm{x}_{\alpha}\right)$. In the case where the real traffic level is higher e.g., it reaches the maximum traffic level $\mathrm{x}_{\max }$, the flat rate pricing creates (maximum) losses equal to $\mathrm{VC}\left(\mathrm{x}_{\mathrm{p}}\right)-\mathrm{VC}\left(\mathrm{x}_{\max }\right)$. Due to the fact that the variable cost is too small compared to fixed cost, the flat rate pricing is not so prone to losses and profits for different traffic levels in short-run. Similarly, in long-run, it assumed that the mobile operator wishes to recover the long run total costs (LRTC) at the traffic level $\mathrm{x}_{\mathrm{p}}^{\prime}$. For smaller traffic levels, the operator gains profits $\operatorname{LRTC}\left(\mathrm{x}_{\mathrm{p}}^{\prime}\right)-\operatorname{LRTC}\left(\mathrm{x}_{\alpha}{ }_{\alpha}\right)$ and for larger traffic level e.g., at the maximum traffic level the network can carry $\left(\mathrm{x}^{\prime}{ }_{\text {max }}\right)$, the operator faces losses LRTC $\left(\mathrm{x}_{\mathrm{p}}{ }^{\prime}\right)$ - LRTC $\left(\mathrm{x}_{\text {max }}^{\prime}\right)$. It seems that the flat rate pricing level has to increase while the traffic level increases, unless more users join the network or the total cost declines. The highest flat rate to be charged is determined by the maximum data traffic level where the total cost is the highest. Therefore, the highest flat rate pricing, not only guarantee the cover of the total cost but also can give some profits to operator if the traffic does not increase to maximum. Based on this, the mobile operator is motivated to convince the users to consume less, but on the other hand, the flat rate pricing itself motivates the users to consume more.
The usage-based pricing is the sharing of the total cost of the network to the data traffic level. Due to the fact that operators usually face economies of scales i.e., the marginal cost is less than average total cost (MC<ATC), the average total cost is very large at small amounts of data traffic and falls as data traffic increases (the long run total cost increases at a decreasing rate as shown in the right part of Fig. 1). Thus, a price $\mathrm{P}$ per unit at ATC i.e., the average cost pricing $(\mathrm{P}=\mathrm{ATC})$ is preferable than a price per unit at MC i.e., the marginal cost pricing $(\mathrm{P}=\mathrm{MC})$. In a market with intense price competition, the mobile operators would charge at the lowest possible price per unit which covers also the total cost. For declining average total cost curves, this price per unit is determined at the maximum data traffic level the network can carry (minimum usage-based pricing). Assuming that the mobile operator wishes to recover the costs at the traffic level $x_{p}$ in short-run, the break-even usage-based price per unit is $\mathrm{P}_{\mathrm{usage}}=\operatorname{ATC}\left(\mathrm{x}_{\mathrm{p}}\right)$, so as $\mathrm{TC}\left(\mathrm{x}_{\mathrm{p}}\right)=\mathrm{TR}_{\text {usage }}\left(\mathrm{x}_{\mathrm{p}}\right)=\mathrm{x}_{\mathrm{p}} \operatorname{ATC}\left(\mathrm{x}_{\mathrm{p}}\right)$. At this price level $\mathrm{P}_{\text {usage }}$ and for a real traffic level $\mathrm{x}_{\alpha}\left(\right.$ where $\left.\mathrm{x}_{\alpha}<\mathrm{x}_{\mathrm{p}}\right)$, the mobile operator has losses per unit which are equal to the difference of the average total costs at the price-determinant traffic level and the real traffic level i.e., total losses $x_{\alpha}\left(\operatorname{ATC}\left(x_{p}\right)-\operatorname{ATC}\left(x_{\alpha}\right)\right)$. In the case where the real traffic level is higher e.g., it reaches the maximum traffic level $\mathrm{x}_{\max }$, the usage-based pricing creates (maximum) profits equal to $\mathrm{x}_{\max }\left(\operatorname{ATC}\left(\mathrm{x}_{\mathrm{p}}\right)-\operatorname{ATC}\left(\mathrm{x}_{\max }\right)\right)$. In long-run, it assumed that the mobile operator wishes to recover the long run total costs at the traffic level $x^{\prime}$. For smaller traffic level e.g., $\mathrm{x}_{\alpha}^{\prime}$, the operator faces losses which are equal to $\mathrm{x}_{\alpha}^{\prime}\left(\operatorname{ATC}\left(\mathrm{x}_{\mathrm{p}}^{\prime}\right)-\operatorname{ATC}\left(\mathrm{x}_{\alpha}^{\prime}\right)\right)$, and for larger traffic level e.g., at the maximum traffic level the network can carry $\left(\mathrm{x}_{\text {max }}^{\prime}\right)$, the operator gains profits $\mathrm{x}_{\text {max }}^{\prime}\left(\operatorname{ATC}\left(\mathrm{x}_{\mathrm{p}}\right)-\operatorname{ATC}\left(\mathrm{x}_{\max }\right)\right)$. The usagebased pricing level is the average total cost which decreases while the traffic level increases. Based on this behavior, the mobile operator is motivated to convince the user to consume at maximum while keeping a high price level determined at low traffic level, but on the other hand the users always consume more with lower prices. If the operator could
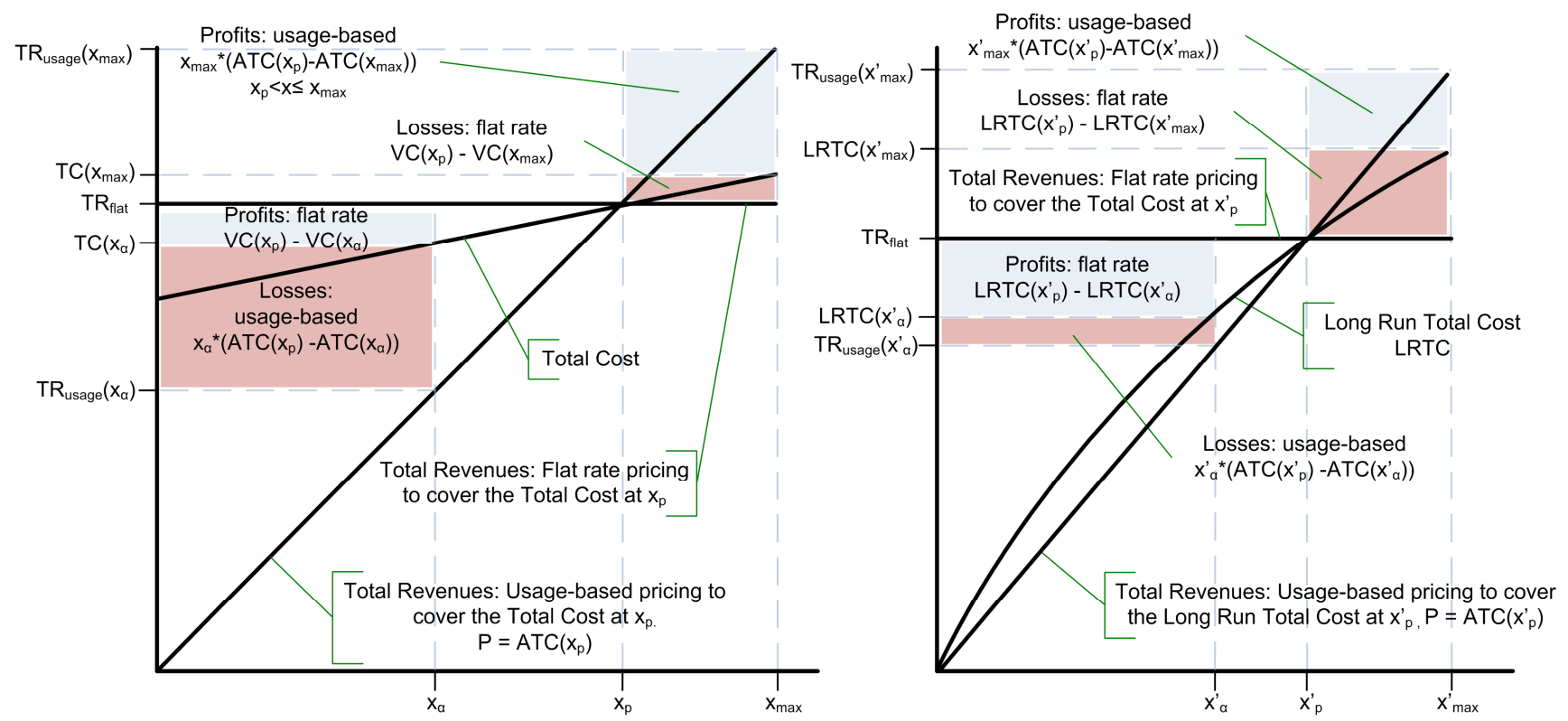

Fig. 1. Cost-based pricing in short-run (left) and long-run (right) 
introduce a pricing system which can estimate the cost per unit dynamically according to the demanded traffic, then the usagebased pricing would always give zero profit. However, such a pricing would be complicated for the end users since they would not really control how much they pay for the service. Such a sophisticated and dynamic pricing system would provide the real market price based on the demand and supply forces. The price per unit could be set differently in different sites. This might have an impact on a better demanded traffic (and spectrum) allocation in geographical area and time (i.e., more even traffic distribution).

\section{CONCLUSIONS}

The marginal and average cost analysis provides essential information for the cost-based pricing. The real traffic level at which the mobile operator wants to ensure cost recovering is important. For real traffic level which is less than this pricedeterminant traffic level, the flat rate pricing create profits, whereas the usage-based pricing create losses (both in shortand long-run). For real traffic level which is more than the price-determinant traffic level, the flat rate pricing creates losses whereas the usage-based creates profits (both in shortand long-run). It seems that the flat rate pricing level has to increase while the traffic level increases, unless more users join the network to share the cost or the total network cost declines. In contrary, adopting the usage-based pricing, the operator is able to decrease the unit price level while the traffic level increases.

\section{REFERENCES}

[1] B.G. Molleryd, J. Markendahl, J. Werding and O. Makitalo, "Decoupling of revenues and traffic - Is there a revenue gap for mobile broadband?", Telecommunications Internet and Media Techno Economics (CTTE), 9th Conference on, pp.1-7, Ghent, 7-9 June 2010.

[2] G. Kesidis, , A. Das and G. De Veciana, "On flat-rate and usage-based pricing for tiered commodity internet services", 42nd Information Sciences and Systems Annual Conference, pp.304-308, 19-21 March 2008.

[3] M. Ljungberg and A. Boll, (2011, February 11), "Mobile broadband second wave - differentiated offerings". Ericsson review 1, [Online]. Available: http://www.ericsson.com/news/110211 second wave 244188811_c

[4] M. Katsigiannis ad C. Valagiannopoulos, "Demand curves and operator strategies in the Finnish mobile broadband market". International Journal of Business Data Communications and Networking (IJBDCN), 10 (1), pp. 30-46.

[5] H. Mitomo, T. Otsuka, and K. Nakaba, "A Behavioral Economic Interpretation of the Preference for Flat Rates: The Case of Post-paid Mobile Phone Services", in: Telecommunication markets: drivers and impediments, in: Contributions to Economics 2009. Physica-Verlag HD, pp. 59-73.

[6] G. Blennerud, (2009, June 10), "Don't worry - Mobile Broadband is profitable". Ericsson Business review 2, [Online]. Available: http://www.ericsson.com/news/090610_ebr_BUSINESS_CASE_mobile broadband_254740099_c

[7] G. Blennerud, G. "Mobile broadband - busting the myth of the scissor effect". Ericsson Business review 2, [Online]. Available: http://www.ericsson.com/ericsson/corpinfo/publications/ericsson busine ss_review/pdf/210/210_strategy_mobile_broadband.pdf 